\section{IN THE DARKER VEIN: BEING A PEDIATRIC ONCOLOGIST}

One pediatric specialty which can use some light in the darkness is pediatric oncology. There is also the fact that pediatric oncologists deal a lot more with veins. This makes it appropriate that I represent the community, writing about the perils (and of course the rewards) of being a pediatric oncologist in a light yet darker vein.

Despite being a different species in the broad genus of pediatricians, the role of pediatric oncologists is little understood. On a personal note, try explaining that to your relatives. "Pediatric Oncology? Do kids get cancer?" -A middle aged uncle who was a casual visitor to my outpatient clinic asked (despite the board outside clearly stating the fact that I am a pediatric oncologist).'They do. But the outcomes are far better compared to adults", I replied. "Must be very depressing to see kids dying of cancer". "Yes it is. But eight out of ten kids survive cancer". And the conversation goes on a loop until one of us gets tired. I chose the road less travelled by and it has made all the difference in my life - the difference of thinking zebra when you hear hoof beats (Yes, I borrowed that from the Immunodeficiency Foundation).

Amongst our fellow pediatricians who are considered benign, we are looked upon as malignant. In our defense, I like to think we are malignant only to those who are malignant (now, that sounds like a punch dialogue in the mass hero movies). We are looked upon as vampires by the kids (not the cute vampires of the Twilight series, but an evil Dracula), but console ourselves saying that we return the blood we draw by the way of repeated transfusions.

The transformation from a pediatrician to a pediatric oncologist is complete when you start to think like this (I refer to these as the Scott criteria* after my mentor Dr.Julius Scott, a great pediatric oncologist): starting piperacillin for febrile neutropenia in a child with dengue and leukopenia, thinking of bone pains when you see a child with growing pains, thinking of neutropenic typhilitis in a child with viral diarrhea, a child with enlarged lymph nodes makes you think of Hodgkin lymphoma as the first differential diagnosis and a child with seborrhea, Langerhans Cell Histiocytosis ( $\mathrm{LCH})$.

On occasion, our extra vigilant attitude strikes gold-we become saviors. These include instances like spotting an innocent looking ear discharge in an infant with seborrhea and working up for $\mathrm{LCH}$, or picking up a sinister Non Hodgkin Lymphoma of the bone masquerading as osteomyelitis. That redeems the lost pride until we encounter the next set of " $D$ " questions.

We are not the only breed of professionals dealing with oncology who undergo this transformation. The pathologist becomes the hero when he detects the malignant cells in the seemingly innocuous 'pus' of a psoas abscess which is actually a lymphoma. Still, we live in constant dread of the words 'inadequate'. Like the infamous duck analogy (for those who don't know- please google "five doctors on a duck hunt") where the pathologist says that the specimen was inadequate even when we think we provided the entire duck. Unlike the clash of egos between pediatricians and pediatric surgeons, pediatric surgeons and pediatric oncologists make a happy couple and they know what we want to keep us happy. 'The case of the missing node' is an extremely rare incident when the draining lymphnodes required to be sampled for staging are missed!

I wish the phrase Primum non nocere (first, to do no harm) applied to parents as well. The guilt of not being in control of their kids' illness makes parents take extreme measures like pouring gallons of papaya leaf extract juices for thrombocytopenia down the throats of unwilling kids with leukemia. Then there are parents who display an ostrich attitude. I recall a case of a child with febrile neutropenia brought to us leisurely on the third day of fever (when actually it is a medical emergency). On being questioned, the parent replied, "You asked us to bring him if he had 'persistent fever', but his fever subsides with every dose of paracetamol". I still cannot fathom whether it was a case of denial or that I needed to improve my communication skills.

At the end of the day, kudos to the pediatric oncologists and pediatricians out there who inspired me to join 'the order of the phoenix', the kids who rise from the ashes after being through chemotherapy, the parents who have the 'never ever give up' attitude and all the others who help them. Blood is thicker than water and to us- the pediatric oncologists, blood is thicker than normal saline, and colloids. And the bond we share with the family is sacred.

(*Not real scientific criteria, but representation of the author's perspective on the thought process of pediatric oncologists.)

AJeitha Loganathan Pediatric Hematology and Oncology G Kuppuswamy Naidu Memorial Hospital, Coimbatore 641 037, Tamil Nadu, India. drajeitha@gmail.com 